\title{
Impact of a diabetic foot care education program on lower limb amputation rate
}

\author{
This article was published in the following Dove Press journal: \\ Vascular Health and Risk Management \\ 7 October 2010 \\ Number of times this article has been viewed
}

\author{
Abdullah M Al-Wahbi \\ Department of Surgery, King Abdulaziz \\ Medical City and King Saud bin \\ Abdulaziz University for Health \\ Sciences, Riyahd, Kingdom of Saudi \\ Arabia
}

Background: Diabetic foot complications are a leading cause of lower extremity amputation. With the increasing incidence of diabetes mellitus in the Arab world, specifically in the Kingdom of Saudi Arabia, the rate of amputation will rise significantly. A diabetic foot care program was implemented at King Abdulaziz Medical City in Riyadh, Saudi Arabia, in 2002. The program was directed at health care staff and patients to increase their awareness about diabetic foot care and prevention of complications. The purpose of this study was to perform a primary evaluation of the program's impact on the rate of lower extremity amputation due to diabetic foot complications.

Method: This pilot study was the first analysis of the diabetic foot care program and examined two groups of participants for comparison, ie, a "before" group having had diabetic foot ulcers managed between 1983, when the hospital was first established, and 2002 when the program began and an "after group" having had foot ulcers managed between 2002 and 2004, in the program's initial phase. A total of 41 charts were randomly chosen retrospectively. A data sheet containing age, gender, medical data, and the presentation, management, and outcome of diabetic foot cases was used for the analysis.

Results: The before group contained 20 patients ( 17 males) and the after group contained 21 patients (16 males). There was no difference between the two groups with regard to age and comorbidities. The rate of amputation was $70 \%$ in the before group and $61.9 \%$ in the after group. There was a decrease in the percentage of toe amputation in the after group and an increase in the percentage of below-knee amputation in the before group. However, these changes were not significant.

Conclusion: The program, although evaluated at an early stage, has increased the awareness of both patients and health care staff about the prevention and management of diabetic foot disease, and decreased the rate of lower extremity amputation. We believe that the statistical proof of its impact will be evident in the final evaluation.

Keywords: diabetic foot, prevention, complications, lower limb amputation

\section{Introduction}

Foot complications from diabetes are one of the main causes of amputation and its subsequent physical and emotional problems. Peripheral vessels and nerve disorders may lead to foot ulcers, and superadded infection can cause foot gangrene. This problem is one of the main reasons for admission of diabetic patients to hospital, and leads to billions of dollars in medical expenses worldwide. ${ }^{1,2}$ In Saudi Arabia and the Arab world, the incidence is even higher. ${ }^{3-5}$ Diabetes-related lower extremity conditions that increase the risk for amputation among people with diabetes include peripheral neuropathy, peripheral vascular disease, and infection. ${ }^{6}$ Peripheral neuropathy may cause
Correspondence: AM Al-Wahbi Department of Surgery, King Abdulaziz Medical City and King Saud bin Abdulaziz Medical City, PO Box 22490, Riyadh

I I52I, Kingdom of Saudi Arabia Tel +966 | $2520088 \#|4|$ I 7

Fax +966 | 252005 |

Email alwahbil@hotmail.com 
loss of sensation in the feet, resulting in a patient's failure to perceive foot problems, and may cause development of foot deformities that increase pressure points susceptible to ulceration. Osteomyelitis and gangrene may develop from inadequate blood supply and infection. Risk factors for amputation include being older, male, or a member of certain racial/ethnic groups, having poor glycemic control, having diabetes for a longer period, and practicing or receiving poor preventive health care. ${ }^{\text {? }}$

Lower extremity amputation, a devastating consequence of diabetes, remains a very common outcome of diabetic foot complications. ${ }^{8,9}$ Indeed, people with diabetes are 10-15 times more likely to require lower extremity amputation than nondiabetic individuals, with a $30 \%-50 \%$ higher risk of undergoing a second amputation. Furthermore, the mortality rate for patients undergoing amputation is $6 \%$. Amputation is not only a costly outcome for patients, but also expensive for the health care system. In one estimate, managing one patient with an amputation will cost around $\$ 40,000$ to $\$ 75,000$. $^{10-12}$

A recent national study on the prevalence of diabetes in Saudi Arabia revealed that $25 \%$ of Saudis over 40 years of age have diabetes. ${ }^{13}$ Given these statistics, the economic and social implications are apparent and significant.

The diabetic foot care program implemented at King Abdulaziz Medical City in Riyadh in 2002 is a comprehensive approach to maintaining the health of diabetic patients' feet in order to reduce the lower limb amputation rate, thereby dramatically reducing the cost to patients, society, and the health care system. Knowledgeable and consistent care can help patients avoid the potential problems that may lead to amputation. The patients' continued walking ability and quality of life depend on close inspection, proper footwear, a few specific "do's and don'ts", and the commitment of the medical care team. ${ }^{14}$

The purpose of this retrospective study was to evaluate the initial impact of the program on the rate of lower extremity amputation due to diabetic foot complications.

\section{Methods}

In 2002, a diabetic foot care team was formed to revise and establish a proposed diabetic foot care program. The members were specialists involved in diabetic foot management and professionals who had an interest in the program. The team consisted of a vascular surgeon, a diabetologist, an infectious disease internist, a diabetic educator, surgical and medical nurses, and a general surgeon. The aim of the program was to determine the impact of a diabetic foot education program on the prevention and outcomes of diabetic foot complications in our main hospital and satellite primary care clinics. The objectives were to increase the knowledge of patients and health care staff about diabetic foot care, to increase the skills of patients and staff regarding methods for diabetic foot care in order to prevent and manage diabetic foot lesions, and to encourage health care staff to undertake regular foot examination and foot care education in their practice.

The program included foot care education for health care staff, which included the following elements: how to stratify and manage patients in low- and high-risk categories, for which a screening data sheet was provided (Appendix 1); how to apply standard wound care practice protocols; and how to follow the guidelines set out in the institution's referral system for patients with either low- or high-risk diabetic foot problems, including early referral of high-risk patients to a specialist. The education methods for health care staff consisted of lectures on diabetic foot care given at regular intervals and in regular diabetic foot workshops. These workshops were one-day activities conducted by the diabetic foot team. All health care providers in our hospital and satellite clinics caring for diabetes patients were permitted to attend. The morning program consisted of didactic lectures with photographic illustrations, as well as interactive discussions. In the afternoon program, the participants divided into groups and rotated among stations. The first station involved hands-on practice on how to assess foot vascularity and was taught by a vascular surgeon. In the second station, a physician instructed participants on how to assess for the presence of neuropathy. The third station was taught by a diabetic foot educator who gave participants general knowledge about the importance of footwear, examples of major amputation caused by improper footwear, and various examples of foot deformities and minor amputations. By the end of 2004, four workshops had been conducted, with a total of 98 participants. Patient education was mainly provided by a diabetic educator, who conducted educational series and distributed educational pamphlets.

The diabetic foot team monitored the program through feedback from health care staff and patients. Questionnaires were conducted at the end of every activity (workshops and lectures) and short questionnaires were given at random time points to evaluate patient and staff knowledge about the program. These were used to evaluate the program and determine how it could be improved. Program information and results were entered in the hospital's data system.

Our aim is to re-evaluate the program's impact at the end of 2012, ie, 10 years after its inception. However, in this primary evaluation, the program's initial results (from 2002 to the end of 2004) were analyzed. 
The sample size for this study was 41 patients at King Abdulaziz Medical City in Riyadh. The hospital uses the International Classification of Diseases, Eighth Revision, Clinical Modification (ICD-8-CM). The ICD-8-CM system provides codes to classify a wide variety of signs, symptoms, abnormal findings, complaints, social circumstances, and external causes of injury or disease. After approval from the research committee at the hospital and the university, we chose diabetic foot ulcers and cellulitis as codes with which to collect the sample populations.

For this first analysis, a total of 41 charts were randomly chosen and retrospectively reviewed. Twenty belonged to patients who presented with diabetic foot complications between 1983 and 2002 (the "before group"), and 21 to patients who presented with such complications in the program's first two years, from 2002 to 2004 (the "after" group). Patients were evaluated by searching each patient's hospital record for previous admissions and outpatient visits related to diabetic foot complications. A data sheet (Appendix 2) designed to include multiple parameters related to diabetic foot management, was completed by a medical student, and supervised and revised by the author. Demographic data included gender, age, type, complications, duration of diabetes, comorbidities, presentation, investigations, and operative data. Only data pertaining to the objectives of our study were analyzed. The outcome of each group's diabetic foot ulcers, ie, either healing or amputation, was compared. The data were analyzed using the SPSS program (SPSS Inc., Chicago, IL). Chi-square tests were used to compare categoric data and $t$-tests were used for both categoric and continuous measures. Statistical significance was declared for one-tailed $P$ values of 0.05 .

\section{Results}

For the purpose of this evaluation, data pertaining to the objectives of our study were analyzed. Theses were demographic data, diabetes duration, risk factors for development of diabetic foot complications, clinical presentation, and the outcome of the diabetic foot complication. Males comprised $76.2 \%$ of the after group and $85 \%$ of the before group. The mean age was 61.1 years for the after group and 58.6 years for the before group. The mean duration of diabetes in both groups was not significant. In the after group, the mean duration was 16.83 years, with a standard deviation of 8.34 years, with nine patients missing documentation of diabetes duration. In the before group, the mean duration was 13.29 years with a standard deviation of 10 years, with four undocumented patients (Table 1). There were no neuropathies in the before group, while $23.8 \%$ of the after group had neuropathies. There were also no vascular problems in the before group, while $4.8 \%$ of the after group had vascular problems. All patients in the after group presented with an ulcer, compared with $85 \%$ of the before group. Patients in the after group also had a higher chance of presenting with gangrene and osteomyelitis (63.3\% and $42.9 \%$, respectively), (Table 2 ). The overall amputation rate was higher in the before group at $70 \%$ than in the after group ( $70 \%$ versus $61.9 \%$, respectively). Toe amputation was lower in the after group at $28.6 \%$, while below-knee amputation was higher in the before group at $33.3 \%$ (Table 3 ).

\section{Discussion}

The study shows that there was an $8.1 \%$ reduction in amputation rate after implementation of the program, but this was not statistically significant. The percentage of the cases that required amputation at the level of the toes was actually lower in the before group, while the percentage of patients who required amputation at below-knee level was higher in the after group. In addition, one case required above-knee amputation, which represents $5 \%$ of the before group. We observed that there were no neuropathies in the before group, while $23.8 \%$ of the after group had neuropathies. There were also no vascular problems in the before group, while $4.8 \%$ of the after group had vascular problems.

The literature is replete with studies demonstrating the major impact of increasing patients' and health care providers' awareness about foot care and changing their behaviors and practices regarding the prevention of ulcers and amputation. For instance, Lavery et al found that implementing a lower extremity disease management program consisting of screening and treatment protocols for diabetic members in a managed care organization decreased the incidence of amputations by $47.4 \% .{ }^{15-19}$ Studies from several countries have shown that increasing awareness of diabetic foot care, as well as its prevention and proper management, resulted

Table I Patient demographic data, comorbidities, and complications

\begin{tabular}{|c|c|c|c|}
\hline Characteristics & $\begin{array}{l}\text { After } \\
\text { (2002 to 2004) }\end{array}$ & $\begin{array}{l}\text { Before } \\
(1983-2002)\end{array}$ & $P$ value \\
\hline $\mathrm{n}$ & 21 & 20 & N/A* \\
\hline Men & 16 & 17 & 0.69 \\
\hline Age (years) & $61.1 \pm 13.7$ & $58.6 \pm 10.18$ & 0.49 \\
\hline $\begin{array}{l}\text { Type 2/Type I } \\
\text { diabetes }\end{array}$ & $17 / 3$ & $15 / 1$ & 0.61 \\
\hline Neuropathy (\%) & 23.8 & 0 & 0.027 \\
\hline $\begin{array}{l}\text { Peripheral arterial } \\
\text { disease }(\%)\end{array}$ & 4.8 & 0 & 0.512 \\
\hline
\end{tabular}

Abbreviation: N/A, not applicable. 
Table 2 Presentations and investigations

\begin{tabular}{llll}
\hline Presentation & $\begin{array}{l}\text { After } \\
(\mathbf{2 0 0 2 - 2 0 0 4 )}\end{array}$ & $\begin{array}{l}\text { Before } \\
\mathbf{( 1 9 8 3 - 2 0 0 2 )}\end{array}$ & P value \\
\hline $\mathrm{n}$ & 21 & 20 & \\
Ulcers (\%) & 100 & 85 & 0.329 \\
Gangrene (\%) & 63.3 & 36.4 & 0.272 \\
$\begin{array}{l}\text { Osteomyelitis } \\
\text { of foot X-ray (\%) }\end{array}$ & 42.9 & 38.9 & N/A \\
\hline
\end{tabular}

Abbreviation: N/A, not available.

in a $50 \%$ reduction in major amputation rates. ${ }^{20-22}$ However, those studies are reported from developed countries. Few to none of the developing countries have implemented such a program, although they have a higher incidence of diabetes and diabetic foot complications. To our knowledge, our program is the first attempt to implement such a program in our part of the world.

We believe that the following factors might have affected our results. The differences in neuropathy, vasculopathy, and other risk factors for diabetic foot complications were mainly due to highly deficient chart documentation in the before group, which demonstrates the low awareness of the diabetic foot problem in general. Despite this, the encouraging finding was that all patients in the after group presented with a foot ulcer. This could be due to the increased awareness of the general practitioners or other front-line physicians who participated in the program and became more aware of the importance of referring patients with early ulcers to a specialist. In addition, patients educated in the program learned to seek immediate medical advice when they found any lesions on their feet. This could explain the lower percentage of toe amputation in the after group, which may have decreased due to early management of foot ulcers. On the other hand, the after group had a higher percentage of below-knee amputation. This could be explained by the random selection of charts or by the presentation of patients from other cities or hospitals with no foot care program (because our hospital is a tertiary

Table 3 Amputation level

\begin{tabular}{llll}
\hline $\begin{array}{l}\text { Amputation } \\
\text { level }\end{array}$ & $\begin{array}{l}\text { After } \\
(\mathbf{2 0 0 2} \text { to 2004) }\end{array}$ & $\begin{array}{l}\text { Before } \\
(\mathbf{1 9 8 3} \text { to 2002) }\end{array}$ & P value \\
\hline $\mathrm{n}$ & 21 & 20 & \\
$\begin{array}{l}\text { Overall } \\
\text { amputation (\%) }\end{array}$ & 61.9 & 70 & 0.314 \\
$\begin{array}{l}\text { Toe level (\%) } \\
\begin{array}{l}\text { Below-knee } \\
\text { level (\%) }\end{array}\end{array}$ & 28.6 & 40 & $\mathrm{~N} / \mathrm{S}$ \\
$\begin{array}{l}\text { Above-knee } \\
\text { level (\%) }\end{array}$ & 0 & 20 & $\mathrm{~N} / \mathrm{S}$ \\
\hline
\end{tabular}

Abbreviation: N/S, not significant. centre, difficult or poorly managed cases are often referred). Our initial results did not replicate other international experience, which has established the effectiveness of establishing a diabetic foot care program in reducing the amputation rate. Nevertheless, this was also the experience of some other programs in their initial stages. ${ }^{23,24}$

Given that this was a pilot study, limitations include a small sample size, a short duration of follow-up, and missing data in the charts of both groups. In addition, the after group was chosen too early, so the protocols of the program had not yet been well implemented or disseminated to all health care providers. The poor compliance of patients with follow-up and prevention education is also an important factor. Other factors that are unique to our part of the world no doubt represent an important contribution to the delay in obtaining the required results of the program. These include education (because there is a high percentage of illiterate people in the community), the media (which pays less attention to medical problems here than in other countries), and the common belief that traditional management (herbal medicine, cautery, bloodletting) is more effective than modern medicine. ${ }^{3,5}$ The latter is, in the author's view, the main determining factor.

Based on the results we have seen since 2004, we believe that our program will have a significant impact on reducing the rate of amputation due to diabetic foot complications, and this will be demonstrated in our next evaluation. Patients, health care staff, and even hospital admission censuses are showing a decrease in the rate of advanced diabetic foot complications. Operating room statistics are also showing a decline in amputation procedures. Moreover, general practitioners and endocrinologists are reporting changes in patients' behavior regarding foot care, and patients frequently ask that their feet be checked at all visits. The pattern of referral to our vascular clinic has changed from advanced diabetic foot lesions to early ulcers.

Educating health care staff and patients about diabetic foot complications and increasing their awareness will no doubt have a significant impact on reducing the rate of amputation; however, it will require commitment and patience to achieve the required results, especially in communities where education is still growing, as in developing countries. Achieving these results will encourage hospital administrators and policy makers to support and disseminate the program to other institutions.

Developing countries differ in their amount of resources and level of government support. Our program does not require financial support or advanced resources, so we recommend its use in all developing countries with diabetic foot crises, because it is easily conducted without financial burden. 
It only requires a caring enthusiastic group of health care staff who can adapt the program and tailor it to their capabilities in order for good long-term results to be achieved.

\section{Conclusion}

Although our initial results did not replicate those of other international studies which have shown the effectiveness of diabetic foot care programs in reducing the amputation rate, we have found that this was the experience of some other programs in their initial stages. Therefore, we believe that the second stage of evaluation will demonstrate a significant improvement in the lower limb amputation rate of diabetic patients in our hospital.

\section{Disclosure}

The author reports no conflict of interest in this work, which was presented at the 11th Annual Congress of Asian Society for Vascular Surgery and the Fourth Annual Meeting of the World Federation of Vascular Surgery Societies in 2010.

\section{References}

1. Goodridge D, Trepman E, Embil JM. Health-related quality of life in diabetic patients with foot ulcers: Literature review. J Wound Ostomy Continence Nurs. 2005;32:368-377.

2. Ragnarson-Tennvall G, Apelqvist J. Prevention of diabetes related foot ulcers and amputations: A cost-utility analysis based on Markov model simulations. Diabetologia. 2001;44:2077-2087.

3. Al-Wahbi AM. The diabetic foot in the Arab world. Saudi Med J. 2006;27:147-153.

4. Wrobel JS, Mayfield JA, Reiber GE. Geographic variation of lowerextremity major amputation in individuals with and without diabetes in the Medicare population. Diabetes Care. 2001;24:860-864.

5. Al-Wahbi AM. The diabetic foot in the Arab world. In: Gill G, editor. Diabetes in the Arab World. Cambridge: FSG Communications; 2005.

6. Boulton AJ. The pathogenesis of diabetic foot problems: An overview. Diabetes Med. 1996;13:12-16.

7. Dargis V, Pantelejeva O, Jonushaite A, Vileikyte L, Boulton AJ. Benefits of a multidisciplinary approach in the management of recurrent diabetic foot ulceration in Lithuania: A prospective study. Diabetes Care. 2009;22:1428-1431.
8. Johannesson A. Incidence of lower limb amputation in the diabetic and non-diabetic general population: A 10-year population-based cohort study of initial unilateral, contralateral and re amputations. Diabetes Care. 2009;32:275-280.

9. Calle-Pascual AL, Redondo MJ, Ballesteros M, et al. Nontraumatic lower extremity amputations in diabetic and non-diabetic subjects in Madrid Spain. Diabetes Metab. 1997;23:519-523.

10. Reiber GE, Lipsky BA, Gibbons GW. The burden of diabetic foot ulcers. Am J Surg. 1998;176:5-10.

11. Pelqvist $\mathrm{J}$, Larsson $\mathrm{J}$. What is the most effective way to reduce incidence of amputation in the diabetic foot? Diabetes Metab Res Rev. 2000;16:S75-S83.

12. King LB. Impact of a preventive program on amputation rates in the diabetic population. J Wound Ostomy Continence Nurs. 2008;35:479-482.

13. Al-Nozha MM, Al-Maatouq MA, Al-Mazrou YY, et al. Diabetes mellitus in Saudi Arabia. Saudi Med J. 2004;25:1603-1610.

14. Holstein PE, Sorensen S. Limb salvage experience in a multidisciplinary diabetic foot unit. Diabetes Care. 2009;22:B97-B103.

15. Larsson J, Apelqvist J. Towards less amputations in diabetic patients. Incidence, causes, cost, treatment, and prevention: A review. Acta Orthop Scand. 2005;66:181-192.

16. Lavery LA, Wunderlich RP, Tredwell JL. Disease management for diabetic foot: Effectiveness of a diabetic foot prevention program to reduce amputations and hospitalizations. Diabetes Res Clin Pract. 2005;70:31-37.

17. Calle-Pascual AL, Duran A. A preventive foot care program for people with diabetes with different stages of neuropathy. Diabetes Res Clin Pract. 2002;57:111-117.

18. Malone JM, Snyder M. Prevention of amputation by diabetic education. Am J Surg. 1989;158:520-523.

19. McCabe CJ, Stevenson RC, Dolan AM. Evaluation of diabetic foot screening and prevention program. Diabetes Med. 1998;15:80-84.

20. Moreland ME, Kilbourne AM, Engelhardt JB. Diabetes preventive care and non-traumatic lower extremity amputation rates. J Health Qual. 2004;26:12-17.

21. Assal JP, Mehnert H, Tritschler HJ. On your feet! Workshop on the diabetic foot. J Diabetes Complications. 2002;16:183-194.

22. van Gils CC, Wheeler LA, Mellstrom M. Amputation prevention by vascular surgery and podiatry collaboration in high-risk diabetic and non diabetic patients. The Operation Desert Foot experience. Diabetes Care. 1999;22:678-683.

23. Argis V, Pantelejeva O, Jonushaite A, Vileikyte L, Boulton AJ. Benefits of a multidisciplinary approach in the management of recurrent diabetic foot ulceration in Lithuania: A prospective study. Diabetes Care. 2009;22:1428-1431.

24. Singh N, Armstrong DG, Lipsky BA. Preventing foot ulcers in patients with diabetes. JAMA. 2005;293:217-228. 


\section{Appendices}

Diabetic foot evaluation form: Date : ---------

History

Diabetes mellitus Type I $\square$ Type II on insulin $\square$ Oral agents $\square$ None $\square$

Other diagnoses:

HX foot ulcer $\quad Y \square \quad N \square \quad$ Surgery $Y \square N \square$

Employed $\mathrm{Y} \square \mathrm{N} \square$

Activity: sitting __- $\%$ versus standing/walking __- $\%$

Independent ambulation $\square$ Ambulatory aids

Ambulation distance Unlimited $\square$ Limited

Homebound $\square$ Nonambulatory $\square$

Exercise $\mathrm{Y} \square \mathrm{N} \square$

Other

Sensation/Skin

Monofilament test

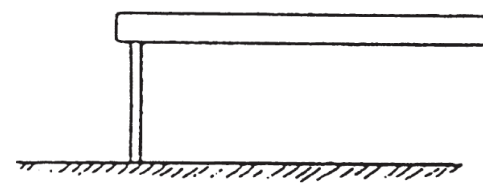

A

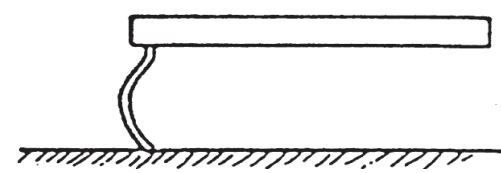

B

Apply sufficient force to cause the filament to bend 


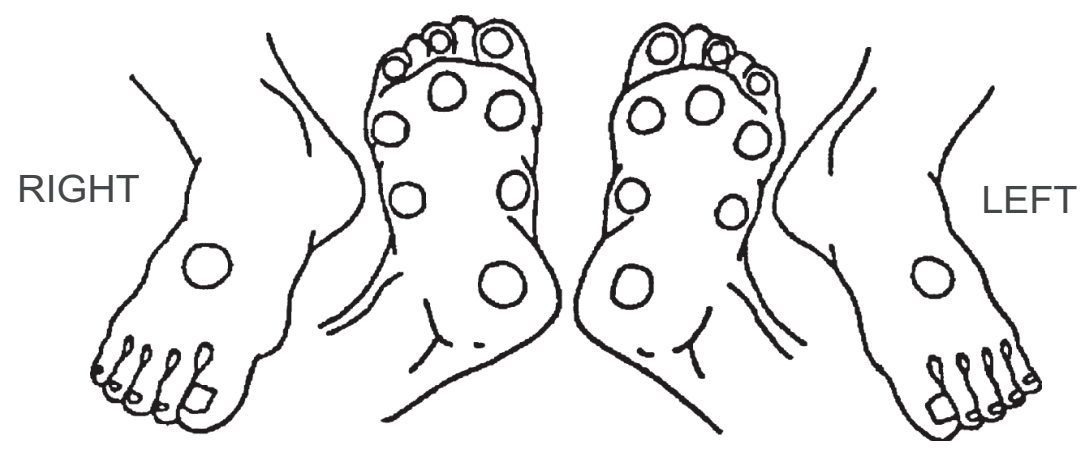

Label: positive (can feel monofilament) negative (cannot $=$ loss of protective sensation)

$\mathrm{D}=$ dryness, $\mathrm{S}=$ swelling, $\mathrm{R}=$ redness, $\mathrm{T}=$ temperature

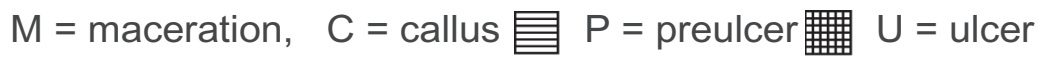

\section{Vascular}

Right

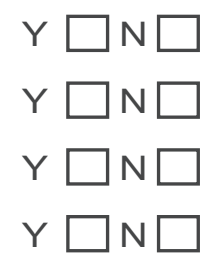

\begin{tabular}{|c|}
\hline Dorsal pedal pulse \\
\hline Posterior tibial pulse \\
\hline Shiny, hairless, atrophic skin \\
\hline Capillary refill $<3 \mathrm{sec}$ \\
\hline
\end{tabular}

Left

$\mathrm{Y} \square \mathrm{N} \square$ $\mathrm{Y} \square \mathrm{N} \square$ $\mathrm{Y} \square \mathrm{N} \square$ $\mathrm{Y} \square \mathrm{N} \square$

Other

\section{Deformities}

Right Left

\section{Footwear}

Standard $\quad \mathrm{Y} \square \quad \mathrm{N} \square \quad$ Prescription $\mathrm{Y} \square \quad \mathrm{N} \square$

Appropriate $\mathrm{Y} \square \quad \mathrm{N} \square \quad$ Worn $\quad \mathrm{Y} \square \quad \mathrm{N} \square$




\section{Assessment}

Foot injury risk

$\square 0$ - No loss of protective sensation

$\square 1$ - Loss of protective sensation

$\square 2$ - Loss of protective sensation and high pressure (callus or deformity) and/or poor circulation

\section{3 - History or foot ulcer or Charcot fracture}

Other

年

\section{Plan}

Signature

Appendix I King Abdulaziz Medical City Diabetic Foot Program screening sheet. 
No:

Admission No:

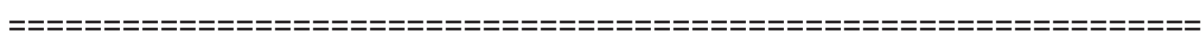

MR:----------------- Age:--------- Gender:---------- Saudi $\square$ Non-Saudi $\square$

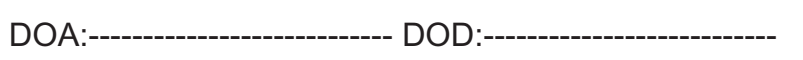

ADMISSION : Elective $\square$ Urgent $\square$ Emergency $\square$ Transfer

ADMITTING SERVICE:

MEDICAL DATA:

Smoking $\square$ Duration:-----------

Diabetes mellitus: $\quad$ Type I $\square$ Type II $\square \quad$ Duration :----------------

Complications: Retinopathy $\square \quad$ Nephropathy $\square \quad$ Neuropathy $\square \quad$ Polyneuropathy

Mononeuropathy $\square$

Diet $\square$ OHD $\square$ OHD + INS $\square$ Beta-blockers $\square$ Other medications:-

Hypertension $\square$ Congestive heart failure $\square$ Ischemic heart disease $\square$ Lipids $\square$ TYPE:

$\square$ FHX $\square$ Ischemic heart disease $\square$ Peripheral vacular disease $\square$ Cerebrovascular accident $\square$ Vasculitis $\square$ Renal failure on dialysis $\square$ Chronic obstructive pulmonary disease $\square$ Others

\section{SYMPTOMS:}

Claudication $\square$ Duration:--------------------- Distance:------------------------------

Rest pain $\square \quad$ Gangrene $\square$

Previous admissions $\square$ Previous surgery $\square$ Date of initial treatment:--------------

EXAMINATION SITES:

Infection $\square$ Abscess $\square \quad$ Cellulitis $\square$ Necrosis $\square \quad$ Ulcer $\square$

Ischemic Changes $\square$ Peripheral neuropathy $\square$ 
PULSES:

\begin{tabular}{|l|l|l|l|l|l|l|}
\multicolumn{9}{|c}{ Right } & Peft \\
\hline & Pulse & Bruit & Doppler & Pulse & Bruit & Doppler \\
\hline Femoral & & & & & & \\
\hline Popliteal & & & & & & \\
\hline $\begin{array}{l}\text { Dorsalis } \\
\text { pedis }\end{array}$ & & & & & & \\
\hline $\begin{array}{l}\text { Posterior } \\
\text { tibial }\end{array}$ & & & & & & \\
\hline
\end{tabular}

Exposed bone $\square$

CAUSES:

Trauma $\square$ Burn $\square$ Trophic $\square \quad$ Neuropathic $\square$

INVESTIGATIONS:

CBC: White blood cells $\mathrm{Hb}$ Platlets Urea Creatinine Cholesterol

Hemoglobin A1c:

CARDIAC ASSESMENT:

CAROTID EVALUATION

ABI: Right Left

TOE PRESSURE: Right Left

X-RAY FOOT:

ANGIOGRAM:

$\square$ Preoperative $\square$ Intraoperative $\square$ Postoperative

$\square$ Angioplasty___________ Stent

Inflow:

Runoff: $\square$ Single vessel

2-3 vessels

$\square$ X-rays

Bone scan

TYPE OF ORGANISM: $\square$ Swab culture and sensitivity $\square$ Tissue culture 
TREATMENT:

Antibiotics: $\square$ Initial

Duration

$\square$ Post culture and sensitivity

Duration

\section{DEBRIDEMENTS:}

DRESSING:

\section{OPERATIVE DATA:}

General anesthetic $\square$ Epidural $\square$ Regional $\square$ Local anesthetic

Revascularization $\square$ Bypass $\square$ Endarterectomy

Graft: $\square$ In situ $\square$ Reversed $\square$ Dacron $\square$ PTFE $\square$ Composite $\square$ Seqential

Patch: $\square$ Vein $\square$ Dacron $\square$ PTFE

Inflow: Site_________ $\square$ Side to side $\square$ End to side $\square$ End to end

Outflow: Site__________ $\square$ Side to side $\square$ End to side $\square$ End to end

*Findings compared with angiogram: $\square$ Same $\square$ Different

\section{AMPUTATION:}

\section{Toe: $\square$ Metatarsal $\square$ Below-knee $\square$ Above-knee}

OTHERS $\square$ Debridement $\square$ Flap $\square$ Skin graft

Postoperative: $\square$ Warfarin $\square$ Aspirin $\square$ Intravenous heparin

Second procedure:

HOSPITAL STAY:

Complications and comments: 
MORTALITY: < 30 days > 30 days Date of death____/_-

Cause of death:

Other causes:

Discussed in morbidity and mortality meeting $\square$ Yes $\square$ No

Filled in by:

Appendix 2 King Abdulaziz Medical City, Diabetic Foot Care Program data sheet.

\section{Publish your work in this journal}

Vascular Health and Risk Management is an international, peerreviewed journal of therapeutics and risk management, focusing on concise rapid reporting of clinical studies on the processes involved in the maintenance of vascular health; the monitoring, prevention and treatment of vascular disease and its sequelae; and the involvement of metabolic disorders, particularly diabetes. This journal is indexed on PubMed Central and MedLine. The manuscript management system is completely online and includes a very quick and fair peer-review system, which is all easy to use. Visit http://www.dovepress.com/ testimonials.php to read real quotes from published authors.

Submit your manuscript here: http://www.dovepress.com/vascular-health-and-risk-management-journal 